\title{
Imagem dialética na cidade - sobre o trânsito de um conceito ao desenho do menos idealista dos objetos
}

Rita Velloso

PUC-Minas

Resumo: A força de uma imagem dialética reside na possibilidade aberta ao habitante, em dada situação de sua vida urbana, de criticar a realidade. Segundo escreveu Benjamin, em tais imagens o fluxo dos acontecimentos "deveria ser subitamente imobilizado, 'congelado', para que a consciência do observador pudesse escapar à tirania da aparência de 'normalidade' e, assim sendo, permitir ao habitante urbano refletir criticamente sobre o seu sentimento atual diante da realida devivida." A imagem dialética - fenômeno que narra uma história desencantada da cidade, caso essa não sucumbisse à forma-mercadoria - dirige-se a uma particular estratégia projetual em arquitetura, na qual a dialética - um despertar histórico da consciência de classe iluminado pelos resíduos da cultura de massa - no que tange à vida urbana, tem por tarefa despertar a consciência dos que dominam a construção da cidade e dos que são por ela dominados.

Palavras-chave: Imagem dialética. Fantasmagoria urbana. Vida cotidiana.

"A fantasmagoria da cultura capitalista alcança seu desdobramento mais brilhante na exposição universal de 1867”, quando o Segundo Império está no auge do seu poderio, dirá Benjamin na Exposé de 1935. Durante o século XIX Paris é sem dúvida o centro do capital, mas naquele ano de 1867 muitos fatos arquitetônicos expressavam de modo especial a sobrelevação da capital francesa do universo econômico e cultural de que fazia parte. "A grande cidade da última metade do século XIX, a metrópole da era industrial, assumiu subitamente sua forma típica em Paris, entre 1850 e 1870. Em nenhuma outra cidade deste período, mudanças resultantes do desenvolvimento da indústria ocorreram com tamanho ímpeto."

Em seu espírito a Exposição era devedora do consumo- ou melhor, da instantânea cultura do consumo - transformado numa festa frenética, conforme assinalou Benjamin em suas notas. ${ }^{2}$ No auge do Império de Napoleão III Paris afirmava-se como capital do luxo e da moda, o que, entretanto, já perdurava há algumas décadas. $\mathrm{O}$ que as exposições inauguram, afirma Benjamin, é uma fantasmagoria "a que o homem se entrega para divertir-se." ${ }^{3}$ A indústria do luxo não começara com as exposições universais, mas, sim, com os chamados magasins de nouveautés, as 
passagens cobertas, cujo próprio auge se dera entre os anos 1820-1840. Tais edifícios, no início, eram ruas cobertas em rotas de pedestres em meio aos edifícios e caminhos, abrigando lojas luxuosas, sem qualquer projeto arquitetônico ou modelo direto que houvesse gerado sua tipologia. Contudo, surgidos no contexto de emancipação da burguesia, eram um verdadeiro sucesso de público - lugares frequentados por toda Paris. Ao mesmo tempo em que são lugares de passagem, logo, espaços articuladores da transição de interior/exterior, do veloz e do vagaroso, as arcadas, estudadas por Benjamin durante mais de uma década, são lugares de permanência. Passagens entre ruas, no coração da cidade, eram lugares da circulação e da acumulação capitalista, onde se dava a mistura pervagante das classes sociais - em relações breves, mas repetidas no cotidiano da cidade-capital, intersectando atividades de negócios, consumo, entretenimento, política e informação. ${ }^{4}$ Uma passagem era lugar em que a burguesia vinha para comprar de tudo, o povo vinha para olhar tudo o que não podia comprar e, o mais importante, o anonimato era garantido a todos.

O destino da cultura no século XIX foi precisamente seu caráter de mercadoria, muito bem encarnado na grande cidade. Para Benjamin, a grande cidade era expressão da cultura da reificação no apogeu do capitalismo. As condições econômicas, sob as quais uma sociedade existe, determinam-na não apenas em sua existência material e na superestrutura ideológica, "elas encontram também sua expressão." ${ }^{\circ}$ Se expressão é representação mediada por processos subjetivos imaginativos e por uma interpretação consecutiva, pode-se compreender o que Benjamin julgou reconhecer na cidade como a expressão das abstrações do valor - os lugares urbanos cujo caráter expressava a "nova natureza" do século XIX (a cultura capitalista industrial).

Benjamin afirma que "o $[\mathrm{x}]$ das forças produtivas de uma sociedade não é determinado somente por suas matérias primas e instrumentos, mas também por seu meio ambiente" ${ }^{6}$ e pelas experiências que uma tal sociedade aí faz. A cidade grande é, então, pensada como espaço social artificial - obra produzida de forma coletiva - cujo ambiente encapsula os elementos e produtos das estruturas econômicas e sociais modernas. A seu ver, a cidade-capital é o lugar privilegiado para a interpretação dessas estruturas.

A cultura da mercadoria no século XIX é um mundo de sonho e, não obstante sua forma distorcida, é a materialização de aspirações genuínas. A cidade grande 
oitocentista, Paris sobremaneira, é o lugar do progresso eminente com seus edifícios que são fantasias tecnológicas do Segundo Império. Os objetos urbanos são para Benjamin "imagens de sonho, hieróglifos de um passado esquecido."7

A arquitetura é a evidência mais importante da mitologia latente de uma sociedade, dizia Benjamin. É imagem com a qual uma sociedade produtora de mercadorias representa a si mesma, "e acredita compreender-se quando faz abstração do fato de que ela produz mercadorias". Então a arquitetura é, ela mesma, uma fantasmagoria: um objeto mágico, cuja imagem cristaliza uma percepção cultural do modo de produção; em outras palavras, é o modo como a sociedade lida com a organização social da produção. A arquitetura é uma imagem na consciência coletiva, transfigurando o produto social, e como tal é consumida; todo traço da sua própria produção deveria idealmente desaparecer, ela deveria parecer jamais ter sido feita, jamais revelar o trabalho que exigira. Nesse sentido, as vitrines nas passagens e lojas são o correlato do desenho haussmaniano para o "embelezamento estratégico".

O coletivo interpreta as condições econômicas de sua vida "e as explica, elas encontram sua expressão no sonho e sua interpretação no despertar." ${ }^{8}$ As passagens revelavam o sonho da burguesia e por isso Benjamin as chamou "a mais importante arquitetura do século XIX." "9 Ele se dispõe a examiná-los, o sonho e o edifício. "Tal panorama ideal de um tempo primevo mal deixado para trás revela-se ao olhar pelas passagens encontradas em todas as cidades. Aqui vive o último dinossauro da Europa, o consumidor. Nas paredes destas cavernas viceja a mercadoria como flora imemorial, urdindo as relações mais desordenadas, como um tecido de tumores."10

A experiência de se frequentar as passagens compunha o universo do sonho da burguesia, pois todo um universo espiritual se expressava ali. Ora, se Benjamin problematiza a alienação do sujeito humano e do ser humano como espécie sob as condições da produção industrial capitalista, abundância, progresso e liberdade - todos e cada um dos desejos ditados pela compulsão-, encontram sua forma material distorcida na arquitetura. A metrópole se auto-proclama o zênite do progresso e da civilização.

As passagens, Walter Benjamin as enxergou como miniaturas da cidade burguesa, tal como essas cidades deveriam ter sido segundo o imaginário inimputável da mesma burguesia: o entorno deslumbrante dos passeios em meio às mercadorias, em 
que o mundo da produção desaparecia e ficava só o espaço da circulação, do consumo, da compra e da venda. O sonho da burguesia se corporificava: o luxo do paraíso encobria o inferno da exploração. (...) A burguesia que se expressava nas passagens era anterior ao imperialismo, ostentava uma convicção excessiva na nobreza e na universalidade de sua causa. $^{11}$

A cidade grande é parte da fantasmagoria da modernidade, enquanto locus eminente dos seus mitos. Os edifícios e os objetos da metrópole são imagens de sonho por que representam aspirações jamais concluídas. A fantasmagoria urbana apresenta, assim, sua dualidade: tanto é utopia quanto cinismo - espaço da frustração, da inversão e distorção dos sonhos. O desejo pela mercadoria e a concomitante mercantilização do desejo caracterizam as experiências-chave da vida metropolitana, enraizadas na formamercadoria: esquecimento, reificação e fetichização. Os desejos utópicos encarnam sua atualização distorcida na arquitetura da cidade, particularmente em arcadas, estações, exposições e lojas de departamento com suas mercadorias refinadas. Estes edifícios, configuradores da paisagem urbana, quando criticamente compreendidos, desvelam a metrópole como lugar da loucura e da decepção, da ignorância e da desumanização, do mito e da miopia. Reconhecê-la como fantasmagoria, esse é o momento destrutivo da crítica benjaminiana à cidade.

A cidade, contudo, estimula num indivíduo a memória, misturando esquecimento e lembrança, e permite-lhe a experiência (Erfahrung), num sentido forte e esse é o movimento produtivo da crítica de Benjamin à arquitetura urbana -, pois, para ele, a rememoração (Eingedenken) liberta as coisas cotidianas do feitiço da mercadoria. ${ }^{12}$ Os impulsos utópicos de antigas gerações ficam incrustadas nos produtos recentes e inovações da sociedade capitalista. São a Ur-Geschichte do passado recente, os elementos de uma utopia que precisam ser libertados, redimidos e realizados no presente. Mas, para desmitificar as fantasmagorias, é necessário tornar evidente que coisas sempre são a expressão de processos. Um produto fantasmagórico é um produto ideológico que pode operar para a crítica da ideologia, pois, se a fantasmagoria faz a mediação enganosa do antigo e do novo, por meio da crítica é possível usar as forças que produziram no sujeito esse "enfeitiçamento" - a atitude contemplativa de que falava Lukács - para romper o efeito ideológico deste último. 
A crítica da ideologia, tal como concebida por Benjamin, dava-se em meio à práxis, modelada em práticas terapêuticas, "herdeira da iluminação profana e da imagem dialética que é uma imagem de sonho."13 O conceito de imagem dialética é uma das articulações vitais da filosofia benjaminiana. No Trabalho das Passagens é o elemento chave, em que se entrelaçam o sonho e o despertar, juntando o passado e o presente numa temporalidade distinta de ambos. ${ }^{14}$

Por meio da imagem dialética, elemento que sintetiza o momento produtivo da sua crítica à cidade, Benjamin afasta-se da tradição da intuição intelectual e da evidência em direção a um conceito de verdade fundado na fragmentação constitutiva da linguagem, criando uma concepção original do tempo a partir de uma forma da percepção "imagética" . Não é que o tempo passado jogue luz sobre o acontecimento presente ou que o fenômeno atual ilumine o mundo passado; trata-se, na imagem dialética, daquilo em que se reúne, num lampejo, o que já foi e o agora. Em outras palavras, imagem é a dialética interrompida (Dialektik im Standstill). ${ }^{15}$ A imagem dialética benjaminiana é uma pausa, um momento de interrupção e iluminação, na qual passado e presente reconhecem-se mutuamente através do vazio que os separa e a dialética transgride as fronteiras da representação tradicional: com a função de remontar o sentido das imagens é como um relâmpago, nunca um sistema.

Benjamin confere às imagens papel interpretativo, na medida em que essas "propõem concretamente assuntos conceituais referentes ao mundo exterior ao texto.",16 A força da imagem dialética está em que ela oferece ao indivíduo - que observa ou participa de uma dada situação no cotidiano de sua vida urbana - a possibilidade de criticar a realidade: segundo Benjamin, em tais imagens o fluxo dos acontecimentos “deveria ser subitamente imobilizado, 'congelado', para que a consciência do observador pudesse escapar à tirania da aparência de 'normalidade' e pudesse refletir criticamente sobre o sentimento atual da realidade observada." 17

Os escritos sobre o cotidiano de uma cidade não são algo isolado no conjunto dos textos de Walter Benjamin, ao contrário, são uma intensificação e desenvolvimento do seu conceito de que "o mundo dominado por suas fantasmagorias é modernidade", ${ }^{18}$ pois enquanto locus da experiência moderna, edifícios e situações urbanas - seja em Paris, Moscou ou Berlim; Marselha, Nápoles ou Ibiza - vão informar seus escritos filosóficos, críticos e estéticos. ${ }^{19}$ A grande cidade realiza a possibilidade do filosofar 
benjaminiano, em que nada há que não possa ser transformado em objeto de observação minuciosa $^{20}$ e, afinal, desenvolvido a partir do cotidiano. É plausível afirmar que a análise do cotidiano por Walter Benjamin faz-se numa estratégia do pensamento que "desierarquiza" a realidade, pois, para o filósofo "não há nada que possa ser distinguido como primeiro, inicial, primordial. (...) Cada célula leva para tudo, para o que é outro e vizinho. ${ }^{21}$ Benjamin entende que as células da vida social e cultural necessitam de uma decodificação, somente possível no "cosmos de correspondências" em que se configura uma grande cidade. Na crítica benjaminiana desenha-se uma urdidura de relações sociais, fenômenos culturais e teorias, em que a cidade é o fio da trama causando a junção e a comunicação de todas as partes entre si. A propósito desse aspecto, Klaus Garber pondera que o caráter inconcluso do Trabalho das Passagens - citações reunidas em notas e fragmentos de minuciosa organização - é antes necessário que casual, pois a aproximação a essas partes somente se dará de forma assintótica. ${ }^{22}$ Ora, a geometria da imagem de Garber - a curva assintótica - é muito feliz na tradução do modo de apresentação da cidade: esta somente se põe para o pensamento na experiência do cotidiano, e decifrar sua dialética imagística exige se aproximar, até onde houver possibilidade, para enxergar através da opacidade. Contudo, enquanto método, tal aproximação não é uma opção dentre muitas; pelo contrário, é exigência e condição necessária no processo de conhecimento de um objeto refratário à sistematização.

Segundo uma interpretação de Jeanne-Marie Gagnebin, a lida com o cotidiano consiste em importante vertente do pensamento benjaminiano - o modo como o filósofo reúne e coleciona fenômenos esparsos, "elementos de um mundo em miniatura", 23 desvendando o significado do aparentemente insignificante. Esta experiência de destruição e restituição do sentido, assinala Gagnebin, marca todo texto benjaminiano: a atenção concentrada no detalhe - à primeira vista sem importância ou em cada objeto estranho, extremo, desviante.

Por meio da imagem surgida no cotidiano é que se desperta para a compreensão e a crítica da cidade. As imagens dialéticas são fenômenos representados nos decadentes objetos cotidianos da capital do século XIX e o que fazem é contar uma história desencantada da burguesia, história da cidade como poderia ter sido caso não sucumbisse à forma-mercadoria. Ora, se é concebida como um despertar histórico da consciência de classe, "iluminado pelos resíduos da cultura de massa", ${ }^{24}$ então a função 
da dialética, no que tange à vida urbana, é despertar a consciência de seus habitantes, todos, os que dominam a construção da cidade e os que são por ela dominados..

\begin{abstract}
The strength of dialectic images stems from the possibilities they offer urban dwellers to criticize reality in certain situations of urban life. According to Benjamin, in these images, the flow of events "should be suddenly immobilized, 'frozen', so as the observer's awareness can escape the tyranny of a false image of 'normality' and, as a result, develop a critical thinking about his actual feeling regarding the experience of reality." The dialectical image - a phenomenon that narrates a disenchanted history of the city, in case it does not turn into commodity-form - concerns a particular architectural design strategy in which dialectics a historical awakening of class consciousness enlightened by the residues of mass culture -, as to urban life, is assigned the task to arouse consciousness of both the ones who rule the production of urban space and the ones who have their lives ruled by urban space configurations.
\end{abstract}

Keywords: Dialectical image. Urban phantasmagory. Everyday life.

\title{
Referências Bibliográficas
}

BENJAMIN, Walter. Passagens. Tradução de Irene Aron e Cleonice Paes Barreto Mourão. Belo Horizonte: Ed. UFMG; São Paulo: Imprensa Oficial do Estado de São Paulo, 2006.

BUCK-MORSS, Susan. Dialética do olhar. Walter Benjamin e o projeto das Passagens. Trad. Ana Luiza de Andrade. Belo Horizonte: Editora UFMG; Chapecó/SC: Editora Universitária Argos, 2002.

CAYGILL, Howard. The experience of the city. In: CAYGILL, Howard. Walter Benjamin: The colour of experience. London: Routledge. 1998. p.118-148.

COHEN, Margaret. Walter Benjamin and the Paris of Surrealist Revolution.Berkeley: University of California Press, 1993.

GAGNEBIN, Jeanne Marie. Por que todo um mundo nos detalhes do cotidiano? Revista da USP, São Paulo, v. 15, p. 38-47, set/out/nov 1992.

GARBER, Klaus. Por que todo um mundo nos detalhes do cotidiano? Revista da USP, São Paulo, v. 15, p. 38-47, set/out/nov 1992.

GEIST, Johann Friedrich. Arcades: The History of a Building Type. Cambridge, MA: MIT Press, 1983.

GIEDION, Sigfried. Espaço, Tempo e Arquitetura. São Paulo: Martins Fontes, 2004.

KONDER, Leandro. Walter Benjamin. O marxismo da melancolia. Rio de Janeiro: Civilização Brasileira, 1999.

SELIGMANN-SILVA, Márcio. Ler o livro do mundo. São Paulo: Iluminuras, FAPESP, 1999. 


\section{Notas}

${ }^{1}$ GIEDION. Espaço, Tempo e Arquitetura, p. 762.

${ }^{2}$ BENJAMIN. Passagens, [G4,4], p. 217.

${ }^{3}$ BENJAMIN. Paris, a capital do século XIX. Exposé 1935. In: . Passagens, p. 44.

${ }^{4}$ GEIST. Arcades: The History of a Building Type, p.458.

${ }^{5}$ BENJAMIN. Passagens, [Mo, 14], p. 936.

${ }^{6}$ BENJAMIN. Primeira versão e materiais do exposé de 1935, No 12. In: . Passagens, p. 999, [manuscrito 1134].

${ }^{7}$ BUCK-MORSS. Dialética do olhar, 66.

${ }^{8}$ BENJAMIN Passagens, [Mo, 14], p. 936.

${ }^{9}$ BENJAMIN. Passagens. [Do,7], p. 910.

${ }^{10}$ BENJAMIN. Passagens. [ao, 3], p. 903.

${ }^{11}$ KONDER. Walter Benjamin. O marxismo da melancolia, p. 93. Para Konder, o fato de que Benjamin tivesse de atravessar as passagens em seu trajeto diário até a Bibliothèque Nationale, resultara em que ele próprio estivesse afetado pelo convívio com essas formas arquitetônicas.

${ }^{12}$ Os termos aqui utilizados - experiência e rememoração -, que compõem o vocabulário mais essencial da filosofia de Benjamin, serão, cada um deles, objeto de análise nos capítulos subseqüentes, respectivamente, capítulos três e quatro, dos quais constituem o tema central. Por ora, faço uso dos conceitos para demonstrar a questão da cidade como objeto central de preocupação do autor, sem examiná-los em toda sua extensão.

${ }^{13}$ COHEN. Walter Benjamin and the Paris of Surrealist Revolution, p. 252.

${ }^{14}$ GAGNEBIN. Por que todo um mundo nos detalhes do cotidiano?, p. 47.

15 A imagem é dialética paralisada, inconclusa. Sobre a tradução de Standstill, cf. SELIGMANN-SILVA. Ler o livro do mundo, p. 228, nota 7.

${ }^{16}$ BUCK-MORSS. Dialética do olhar, p. 27.

${ }^{17}$ KONDER. Walter Benjamin. O marxismo da melancolia, p. 74.

${ }^{18}$ BENJAMIN. Passagens, p. 77.

${ }^{19}$ CAYGILL.The experience of the city, p. 118.

${ }^{20}$ GARBER. Por que todo um mundo nos detalhes do cotidiano?

${ }^{21}$ GARBER. Por que todo um mundo nos detalhes do cotidiano? p. 3.

${ }^{22}$ GARBER. Por que todo um mundo nos detalhes do cotidiano? p. 43.

${ }^{23}$ GAGNEBIN. Por que todo um mundo nos detalhes do cotidiano? p .6.

${ }^{24}$ BUCK-MORSS. Dialética do olhar, p. 334. 